\title{
Contrasting effects of Deadend1 (Dnd1) gain and loss of function mutations on allelic inheritance, testicular cancer, and intestinal polyposis
}

\author{
Jennifer L Zechel ${ }^{1}$, Stephanie K Doerner ${ }^{1}$, Angela Lager ${ }^{1}$, Paul J Tesar ${ }^{1}$, Jason D Heaney ${ }^{1,2}$ and Joseph H Nadeau ${ }^{1,3^{*}}$
}

\begin{abstract}
Background: Certain mutations in the Deadend1 (Dnd1) gene are the most potent modifiers of testicular germ cell tumor (TGCT) susceptibility in mice and rats. In the 129 family of mice, the Dnd $7^{\text {Ter }}$ mutation significantly increases occurrence of TGCT-affected males. To test the hypothesis that he Dnd $1^{T e r}$ allele is a loss-of-function mutation; we characterized the consequences of a genetically-engineered loss-of-function mutation in mice, and compared these results with those for Dnd $1^{\text {Ter }}$.
\end{abstract}

Results: We found that intercrossing $D n d 1^{+/ K O}$ heterozygotes to generate a complete loss-of-function led to absence of Dnd $1^{K O / K O}$ homozygotes and significantly reduced numbers of Dnd $1^{+/ K O}$ heterozygotes. Further crosses showed that Dnd $1^{\text {Ter }}$ partially rescues loss of Dnd $1^{K O}$ mice. We also found that loss of a single copy of Dnd 1 in Dnd $1^{\mathrm{KO} / \mathrm{+}}$ heterozygotes did not affect baseline occurrence of TGCT-affected males and that Dnd $1^{\text {Ter }}$ increased TGCT risk regardless whether the alternative allele was loss-of-function (Dnd $1^{K O}$ ) or wild-type $\left(D n d 1^{+}\right)$. Finally, we found that the action of DndT Ter was not limited to testicular cancer, but also significantly increased polyp number and burden in the $\mathrm{Apc}^{+/ \mathrm{Min}}$ model of intestinal polyposis.

Conclusion: These results show that Dnd1 is essential for normal allelic inheritance and that Dnd $1^{\text {Ter }}$ has a novel combination of functions that significantly increase risk for both testicular and intestinal cancer.

Keywords: Testicular cancer, Allelic segregation, Intestinal neoplasia, DND1

\section{Background}

Testicular germ cell tumors (TGCTs) are the most common cancer affecting young men. They are disproportionately represented in men aged $20-40$, comprising $\sim 60 \%$ of all cancers in this age group [1], while accounting for only 1.0-1.5 \% of all cancers [2]. The incidence of TGCTs has increased in the last 30 years [3], rising approximately $3 \%$ per year from 1972 to 2002 [4] compared to an overall annual decrease of $0.6 \%$ from 1994-2009 for all cancers in men [5].

Testicular cancer is widely considered to be one of the most heritable forms of cancer [6,7]. Genetic factors contribute significantly to TGCT susceptibility as exemplified by a 4 - to 15 -fold increased risk in the sons and

\footnotetext{
* Correspondence: jnadeau@pnri.org

'Department of Genetics and Genome Sciences, Case Western Reserve University School of Medicine, Cleveland OH 44106, USA

${ }^{3}$ Pacific Northwest Research Institute, 720 Broadway, Seattle, WA 98122, USA Full list of author information is available at the end of the article
}

brothers of affected men, respectively $[8,9]$. With conventional inheritance however, risk should be similar in sons and brothers. The $\sim 4$-fold difference in occurrence of affected sons and brothers implies that other modes of inheritance are involved. Despite strong heritability, known genetic mutations and single nucleotide polymorphisms (SNPs) make only modest contributions to susceptibility, illustrating the genetically complex nature of this disease. The $g r / g r$ deletion, which is a common cause of infertility in men, is associated with increased TGCT risk [10]. But its contribution is modest, occurring in only $3 \%$ of TGCT cases with a family history and $1 \%$ of unaffected individuals [11]. $g r / g r$ results from a 1.6 $\mathrm{Mb}$ deletion at the $A Z F C$ locus at Yq11 of the human $\mathrm{Y}$ chromosome, a region that contains multiple copies of several genes that are involved in male germ cell development including $D A Z$ (deleted in azospermia), BPY2 (basic charge, Y-linked 2) and CDY1 (chromodomain protein, $Y$-linked 1). Effects of the $\mathrm{g} r / g r$ deletion on

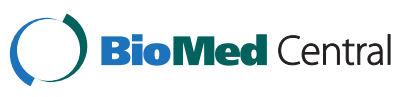


germ cell development and differentiation are largely unknown.

Several single nucleotide polymorphisms (SNPs) are associated with increased TGCT risk in humans. In particular, six studies implicate SNPs that are associated with at least 14 genes: ATF7IP, BAK1, DMRT1, KITLG, SPRY4, TERT, HPGDS, MAD1L1, RFWD3, TEX14, RAD51C, PPM1E, DAZL and PRDM14 [12-19]. Molecular mechanisms remain unclear, in part because many SNPs are located outside the coding region of the associated gene, and in part because the haplotype structure and sequence of these loci have not yet been fully reported. Interestingly, the TERT SNP is also associated with adenocarcinoma [20].

Certain mutations in the Dead End 1 (Dnd1) gene are potent modifiers of TGCT susceptibility in both mice and rats. In the mouse, the spontaneous $D n d 1^{T e r}$ mutation significantly increases TGCT susceptibility in the 129 family of inbred mouse strains. In particular, Dnd1 $1^{\text {Ter }}$ increases occurrence of TGCT-affected males from a baseline of $\sim 5 \%$ in the $129 \mathrm{~S} 1 / \mathrm{SvImJ}$ strain to $17 \%$ in $\mathrm{Dnd1}^{+/ T e r}$ heterozygotes and $94 \%$ in $\mathrm{Dnd1} 1^{\mathrm{Ter} / \mathrm{Ter}}$ homozygotes [21,22]. The Ter mutation is a single base substitution in exon 3, 3' to its single RNA recognition motif (RRM), that transforms an arginine residue to a premature stop codon (Figure 1, see also [22]). The Ter mutation has been proposed to produce an mRNA that is lost by nonsense-mediated degradation owing to the presence of the premature stop codon. This conclusion was based on northern blots of mRNA isolated from TGCTs in Dnd $1^{\text {Ter/Ter }}$ males [22]. But the tissue type (TGCTs) used in this study may not have been appropriate to assess the fate of $D n d 1$ transcripts.

In the rat, a spontaneous mutation has been identified where a $\mathrm{G}$ to A substitution in exon 4 produces a premature stop codon that is thought to result in a 62 amino acid truncation at the C-terminus of the DND1 protein (Figure 1, see also [23]). This mutation leads to germ cell tumors in males and females as well as to spontaneous metastases.

In humans, sequencing of TGCT candidate genes in several large studies failed to detect a significant number of DND1 mutations [4,24]. Of the two SNPs that were identified, one (Glu86Ala) is located within the conserved RRM of DND1 (Glu86Ala). The functional consequences of this mutation on Dnd1 expression and function or on TGCT risk are not known.

Dnd1 has many unique functions. Dnd1 shares significant sequence similarity with $A 1 c f$, a gene that encodes the RNA binding subunit of the Apobec1 cytidine deaminase that edits specific sites in specific mRNAs [22]. Interestingly, DND1 blocks access of specific miRNAs to their 3' target in mRNAs such as $p 27$, LATS2 and TDRD7 [26]. DND1 also binds several pluripotency factor mRNAs
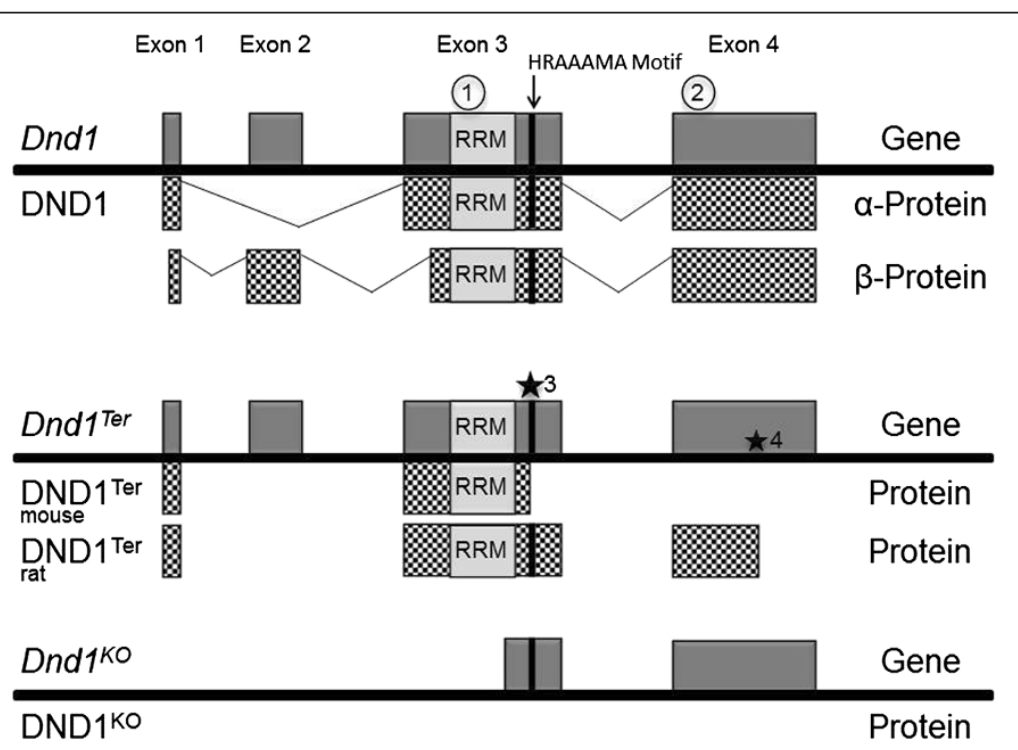

Figure 1 Structure of the $D n d 1, D n d 1^{T e r}$ and $D n d 1^{K O}$ genes and their inferred predicted protein products. Gene arrangements are displayed above the solid line, and the corresponding protein product is displayed below the solid line. Dnd1 has two isoforms: $\alpha$-Dnd 1 and $\beta$ Dnd 1 which differ in the amino-terminus of the protein. Dnd 1 has an RNA recognition motif (RRM) in the C-terminal portion of exon 3. The HRAAAMA motif that is presumably part of the putative ATPase domain is located between amino acids 181-186 in the mouse genome. SNPs identified in human TGCTs include a (1) Glu86Ala [25] and (2) an Asp219Glu [24]. In the mouse, the Ter mutation creates a premature stop-codon at amino acid $178(\star 3)$, which is located 37 nucleotides from the $3^{\prime}$ most exon-exon junction. The rat Ter mutation has the premature stop codon at amino acid $289(\star 4)$ within exon 4. The RRM is intact in both mouse and rat Dnd1 mutants allowing these proteins to possibly recognize and bind to target RNAs; the putative ATPase domain is lost in the mouse Dnd $7^{T e r}$ and truncated in rat Dnd1 ${ }^{\text {Ter }}$. The Dnd ${ }^{K O}$ allele retains the $3^{\prime}$ most portion of exon 3 and exon 4, but does not have a transcriptional start site. 
including Oct4, Sox2, Nanog and LIN28 [27], regulators of cell cycle including LATS2, TP53, p21 and p27 [27,28], apoptotic factors such as BCLX and BAX [27], and is a positive regulator of geminin mRNA translation through binding to its 3' UTR [29]. The role of DND1 in these functions and complexes is unknown. DND1 transports mRNA transcripts from germ cell nuclei to germ cell granules [30]. Finally, Dnd1 is required for primordial germ cell (PGC) survival [31]; PGCs are the stem cell for TGCTs [32]. Together these observations implicate Dnd1 in many aspects of RNA translation control.

The Dnd1 gene in mouse has four exons and encodes an $\alpha$-isoform, which is 352 amino acids, and a $\beta$-isoform, which is 340 amino acids (Figure 1). These isoforms are derived through alternative splicing and differ by 12 amino acids at the amino-terminus of the protein. DND1- $\alpha$ is expressed in early embryos, whereas DND1- $\beta$ is expressed in the germ cells of the adult testis [33]. Both isoforms contain a single RNA recognition motif (RRM) and a highly conserved HRAAAMA motif (unpubl). This 7 amino acid motif is found in most orthologues of Dnd1 and A1cf (JHN, unpubl.). In zebrafish, ATPase activity has been attributed to a variant of this motif in Dnd1 [34].

Several considerations suggest that the assumption that $D n d 1^{T e r}$ leads to loss-of-function is erroneous. In vivo loss of function using morpholinos to reduce expression in zebrafish showed that Dnd1 is required for PGC survival [31], possibly through an ATPase activity [34]. Although TGCTs have been reported in zebrafish [35-37], reduced Dnd1 expression was not sufficient for tumorigenesis. However, because genetic background strongly regulates TGCT susceptibility in mice and rats [23,38-40], absence of TGCTs in the zebrafish study could implicate either the nature of the mutation or genetic background as critical elements determining tumorigenic outcome.

To test whether TGCT susceptibility depends on the nature of Dnd1 mutations, we generated a line of 129/SvImJ$D n d^{K O}$ mice. We found that deficiency of Dnd1 leads to highly biased allelic inheritance and that $D n d 1^{T e r}$ partially restores normal inheritance. We also found that Dnd1 $1^{\text {Ter }}$ acts distinctly from $D n d 1^{K O}$ to increase TGCT risk in a dosage-dependent manner in 129S1/SvImJ males, whereas $D n d 1^{K O}$ did not significantly affect susceptibility. Finally, recent work suggests that susceptibility to both TGCTs and intestinal polyposis share genetic predisposition [41] and that DND1 is normally expressed in the intestine [42-46]. We therefore tested whether Dnd1 $1^{\text {Ter }}$ affects intestinal tumorigenesis and found that $D n d 1^{T e r}$ significantly increases polyp number and burden in $A p c^{+/ M i n}$ mice.

\section{Results}

Loss of Dnd 1 homozygotes and heterozygotes

Unexpected results were found for $D n d 1^{+/ K O}$ intercrosses that were intended to produce $D n d 1^{+/ K O}$ heterozygotes and $D n d 1^{K O / K O}$ homozygotes as well as $D n d 1^{+/+}$wild-type controls for TGCT surveys. The genotypic distribution among adult mice differed significantly from 1:2:1 Mendelian expectations (Table 1; $\chi^{2}=108.4, \mathrm{p}<0.0001$; twotailed test, 2 degrees of freedom). In particular, no $\operatorname{Dnd} 1^{K O / K O}$ homozygotes were observed among 282 offspring (Table 1). To assess the extent of the deviation from expectations, we assumed that the number of $D n d 1^{+/+}$ mice $(\mathrm{N}=120)$ corresponded to expectations, and then extrapolated from this wild-type number to the expected numbers of $D n d 1^{+/ K O}$ heterozygotes $(\mathrm{N}=240)$ and Dnd1 ${ }^{K O / K O}$ homozygotes $(\mathrm{N}=120)$ mice. In addition to a complete deficiency of $D n d 1^{K O / K O}$ homozygotes, only $68 \%$ $(=162 / 240)$ of the expected number of $D n d 1^{+/ K O}$ heterozygotes was found, suggesting that parental $D n d 1^{+/ K O}$ heterozygosity either biased segregation against the $\operatorname{Dnd} 1^{K O}$ allele, or alternatively that partial or complete loss of Dnd 1 function led to lethality for $D n d 1^{K O / K O}$ homozygotes and reduced viability for $D n d 1^{+/ K O}$ heterozygotes.

To examine the developmental timing of genotypic loss, we time-mated heterozygous $D n d 1^{+/ K O}$ males and females, and flushed embryonic day 3.5 (E3.5) embryos from the oviduct. Embryos ( $\mathrm{N}=25)$ were individually cultured for one week before genotyping. The genotypic distribution differed significantly from 1:2:1 Mendelian expectations (Table 2; $\mathrm{X}^{2}=22.4, \mathrm{p}<0.0001$; two-tailed test, 2 degrees of freedom). No Dnd1 ${ }^{K O / K O}$ homozygotes were found among 25 cultured embryos, the number of $D n d 1^{+/ K O}$ heterozygotes was significantly reduced, and no evidence was found for unfertilized oocytes. In addition, the genotypic distributions for E3.5 embryos (Table 2) and for adult mice (Table 1) did not differ significantly (not shown). These results confirm observations found among adult mice and suggests that reduced Dnd1 function either biased segregation, or led to early embryonic lethality. Interestingly, unusual inheritance patterns have also been reported for Apobec1 $1^{K O}$ $D n d 1^{T e r}$ interactions tests [47] and for Apobec1 complementation factor A1cf, the paralog of Dnd1 [48].

To test whether allelic segregation in $D n d 1^{+/ K O}$ is inherently biased, we examined the genotypic representation in reciprocal backcrosses of $D n d 1^{+/ K O}$ heterozygotes to $D n d 1^{+/+}$wild-type mice. Segregation did not differ significantly from 1:1 Mendelian expectations for either

Table 1 Dnd $1^{+/ K O}$ intercross - genotype distribution at weaning

\begin{tabular}{ccc}
\hline Genotype & Observed & Mendelian expectations \\
\hline Dnd $1^{+/+}$ & 120 & 70.5 \\
Dnd $1^{+/ K O}$ & 162 & 141 \\
Dnd $1^{\text {KO/KO }}$ & 0 & 70.5 \\
\hline
\end{tabular}

Dnd $1^{K O}$ segregation in intercrosses and backcrosses. Results are presented after pooling data for both genders (Tables 1, 2, 3, 4), because occurrence of females and males did not differ significantly (not shown). 
Table 2 Dnd $1^{+/ K O}$ intercross - genotype distribution at embryonic day 3.5 (E3.5)

\begin{tabular}{lcc}
\hline Genotype & Observed & Mendelian expectations \\
\hline Dnd $1^{+/+}$ & 16 & 6.25 \\
Dnd $1^{+/ K O}$ & 9 & 12.5 \\
Dnd $1^{K O / K O}$ & 0 & 6.25
\end{tabular}

$\mathrm{Dnd}^{K O}{ }^{K O}$ segregation in intercrosses and backcrosses. Results are presented after pooling data for both genders (Tables 1, 2, 3, 4), because occurrence of females and males did not differ significantly (not shown).

maternal or paternal heterozygosity (Table 3). Interestingly, occurrence of $D n d 1^{+/ K O}$ heterozygous progeny differed in intercrosses versus backcrosses of $D n d 1^{+/ K O}$ heterozygous parents, where a significant deficiency of $D n d 1^{+/ K O}$ heterozygotes was found among intercross but not backcross progeny (Table 3). These results suggest that segregation in each parent is normal and that gametes in each parent are comparably functional in backcrosses but not intercrosses.

Litter size can be used to determine whether unusual inheritance patterns result from embryonic lethality. Litter size should be reduced substantially if deficiency of some genotypes results from lethality. By contrast, if production of gametes or fertilization is biased towards particular alleles, litter sizes should not differ among the various crosses. However, despite significant deviation from the expected genotypic distributions (Table 1), litter sizes did not vary significantly among crosses (Table 3). These results argue against lethality as the cause of the unusual genotypic distributions.

Based on the premise that the DND1 ${ }^{\text {Ter }}$ protein is translated instead of being lost through nonsense mediated degradation, a single copy of $D n d 1^{T e r}$ may be sufficient to at least partially rescue $D n d 1^{K O / K O}$ loss. To test this hypothesis, we intercrossed mice heterozygous for the $D n d 1^{K O}$ and $D n d 1^{T e r}$ mutations and examined occurrence of the four genotypic classes among the resulting offspring (Table 4). The distribution of $D n d 1^{+/+}$, $D n d 1^{+/ K O}, D n d 1^{+/ T e r}, D n d 1^{K O / T e r}$ offspring differed significantly from 1:1:1:1 Mendelian expectations $\left(\chi^{2}=9.1\right.$, $\mathrm{p}<0.03$; two-tailed test, 3 degrees of freedom). The genotype with the largest deviation from expectations was the

Table 3 Dnd $1^{+/ K O}$ segregation in backcrosses versus intercrosses

\begin{tabular}{lcccc}
\hline Cross & $\begin{array}{c}\text { No. } \\
\text { Dnd1 }^{+/+}\end{array}$ & $\begin{array}{c}\text { No. Dnd1 } \\
\text { (expectations) }\end{array}$ & $\begin{array}{c}\text { \% expected } \\
\text { number }\end{array}$ & Litter size \\
\hline Intercross & 120 & $162(240)$ & 67.5 & $5.6 \pm 0.5 \mathrm{n}=18$ \\
Backcross:maternal & 110 & $107(110)$ & 97.2 & $5.8 \pm 0.4 \mathrm{n}=30$ \\
Backcross:paternal & 100 & $96(100)$ & 96 & $5.2 \pm 0.4 \mathrm{n}=19$ \\
\hline
\end{tabular}

Dnd ${ }^{K O}$ segregation in intercrosses and backcrosses. Results are presented after pooling data for both genders (Tables 1, 2, 3, 4), because occurrence of females and males did not differ significantly (not shown).

* Mendelian expectations based on $D n d 1^{+/+}$; litter size (mean $\pm \mathrm{SEM}, n$ is the number of litters).
Table 4 Interaction between $D n d 1^{T e r}$ and $D n d 1^{K O}$

\begin{tabular}{lcc}
\hline Genotype & Observed & Mendelian expectations \\
\hline Dnd $1^{+/+}$ & 40 & 32.5 \\
Dnd $1^{+/ K O}$ & 41 & 32.5 \\
Dnd $1^{+/ T e r}$ & 29 & 32.5 \\
Dnd $1^{\text {KO/Ter }}$ & 20 & 32.5 \\
\hline
\end{tabular}

$D$ Dnd $1^{K O}$ segregation in intercrosses and backcrosses. Results are presented after pooling data for both genders (Tables 1, 2, 3, 4), because occurrence of females and males did not differ significantly (not shown).

Male progeny $(\mathrm{N}=130)$ from crosses between $\mathrm{Dnd} 1^{+/ T e r}$ and $D n d 1^{+/ \mathrm{KO}}$ mice.

$D n d 1^{K O / T e r}$ heterozygote, which supports the hypothesis that the DND1 ${ }^{\mathrm{Ter}}$ protein is translated and retains sufficient functionality to enable at least partial viability of animals in the absence of wild-type DND1; if Dnd1 ${ }^{\text {Ter }}$ conferred loss of function, then loss of both $D n d 1^{K O / K O}$ and $D n d 1^{K O / T e r}$ should have been found.

\section{Dnd1 mRNA levels in Dnd $1^{+/ K O}$ males}

To determine whether the $D n d 1^{K O}$ allele leads to reduction of Dnd1 mRNA, Dnd1 transcript levels were measured in heart and testis from $D n d 1^{+/ K O}$ and wildtype littermate control males that were 6-8 weeks old. Dnd $1^{+/ K O}$ mRNA levels were significantly reduced in heart $(0.41 \pm 0.12 ; \mathrm{t}=3.1, \mathrm{p}<0.05$; two-tailed $\mathrm{t}$-test, $\mathrm{n}=7)$ and substantially reduced in testis $(0.56 \pm 0.19 ; \mathrm{n}=7)$ compared to their wild-type littermate controls $(1.0 \pm$ 0.06 and $1.0 \pm 0.26 ; \mathrm{n}=3$ and 7 , respectively) (Figure 2). Dnd1 mRNA levels from Dnd1 ${ }^{\text {Ter/Ter }}$ hearts (1.33 \pm 0.26 ) did not differ significantly from wild-type controls. Testis samples were not tested because severe germ cell

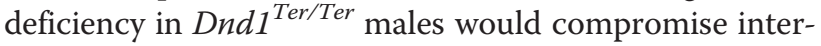
pretation of any results $[21,22,36]$. These results confirm

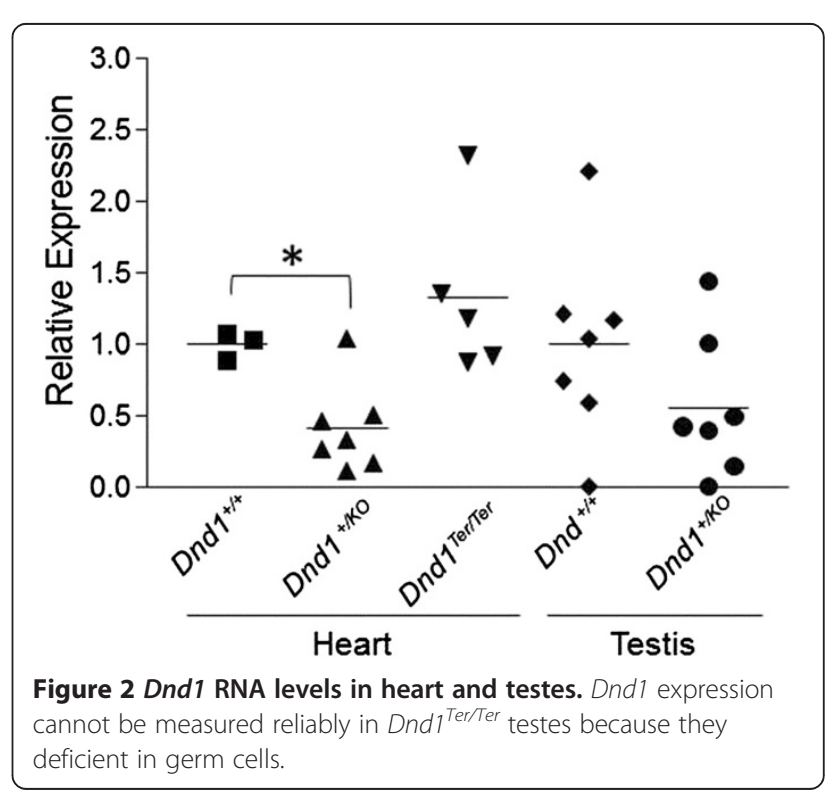


that $D n d 1^{K O}$ but not $D n d 1^{T e r}$ mice showed reduced Dnd1 mRNA levels.

Germ cell numbers and fecundity in Dnd1-deficient males We next sought to test whether $D n d 1^{T e r}$ and $D n d 1^{K O}$ alleles induce similar effects on PGC numbers in testes of heterozygous and wild-type littermates from the $D n d 1^{K O}$ line. Testes from $D n d 1^{+/ T e r}$ males showed modest but significant reductions in germ cell numbers and testis weight $[22,49]$. We weighed testes from 6-10 week old $D n d 1^{+/ K O}$ males and their wild-type $(+/+)$ littermates to determine if they were phenotypically similar to those from $D n d 1^{+/ T e r}$. Testes from wild-type males weighed an average of $4.43 \pm$ $0.88 \mathrm{~g}$, which was similar to the average testes weight of $4.44 \pm 0.69 \mathrm{~g}$ in $D n d 1^{+/ K O}$ heterozygotes (Additional file 1: Figure S1A). These results suggest that germ cell numbers were not significantly reduced in $D n d 1^{+/ K O}$ males. Histological analysis confirmed these results for both $D n d 1^{+/ T e r}$ and $D n d 1^{+/ K O}$ males (Additional file 1: Figure S1B \& C). Finally, both male and female heterozygotes for the $D n d 1^{K O}$ allele were fertile as measured by the similar number of offspring produced in backcrosses to $129 \mathrm{~S} 1 / \mathrm{SvImJ}$ (Table 3). Together these results suggest that the $D n d 1^{K O}$ allele did not negatively impact germ cell numbers or fertility.

\section{Dnd1 mutations and TGCT-affected males}

To test whether partial Dnd1 deficiency affects occurrence of affected males, $D n d 1^{+/ K O}$ and their $D n d 1^{+/+}$wild-type control littermates derived from $D n d 1^{+/ K O}$ intercrosses were surveyed for spontaneous TGCTs (Table 5). Significant differences were not detected for occurrence of TGCT-affected Dnd $1^{+/ K O}$ heterozygous and $D n d 1^{+/+}$ wild-type males. By contrast, $39 \%$ of $D n d 1^{+/ T e r}$ males are affected, which is significantly higher than the occurrence of affected $D n d 1^{+/ K O}$ and their $D n d 1^{+/+}$males $(\mathrm{p}<0.0001$; Fisher's exact test, two-tailed, 1 degree of freedom). (This rate for $D n d 1^{+/ T e r}$ males in our colony is significantly higher than published reports [50]. The rate has been consistently higher for several years, without obvious explanation. Because of the study design, this increased rate does not affect results or interpretation in the present work.) Thus, the $D n d 1^{\text {Ter }}$ but not the $D n d 1^{K O}$ mutation increases TGCT risk.

Table 5 Dnd1 genotype and occurrence of males affected with at least one spontaneous TGCT

\begin{tabular}{|c|c|c|c|}
\hline Genotype & Affected & Unaffected & Affected males (\% \\
\hline $\operatorname{Dnd}^{+/+}$ & 8 & 121 & ${ }^{*} 6 \%$ \\
\hline Dnd $1^{+/ K O}$ & 7 & 109 & $* 6 \%$ \\
\hline$\neq$ Dnd $1^{+/ T e r}$ & 35 & 90 & $39 \%$ \\
\hline
\end{tabular}

To test whether the increased occurrence of affected Dnd $1^{\text {Ter/Ter }}$ males was a result of increased $D n d 1^{+/ T e r}$ or the absence of $D n d 1^{+/ K O}$, we crossed $D n d 1^{+/ T e r}$ and Dnd $1^{+/ K O}$ animals to generate compound heterozygous Dnd $1^{\text {Ter/KO }}$ offspring that were surveyed for TGCTs (Table 6). A single copy of Dnd $1^{\text {Ter }}$ increased occurrence of TGCT-affected males from a baseline of 15\% for Dnd $1^{+/+}$wild-type males to $39 \%$ for $D n d 1^{+/ T e r}$ males. A second copy of $D n d 1^{T e r}\left(D n d 1^{T e r / T e r}\right.$ ) further increased occurrence of affected males to $98 \%[21,22]$. We then asked whether the higher occurrence of affected Dnd $1^{\text {Ter/Ter }}$ males was due to the absence of wild-type DND1, or a result of an increased dosage of Dnd $1^{\text {Ter }}$. Compound heterozygous males $\left(D n d 1^{\text {KO/Ter }}\right)$ have a rate that does not recapitulate the rate found for $D n d 1^{\text {Ter/Ter }}$ homozygotes (35\% versus 97.8\%, respectively) (Table 6). Instead, the rate for compound heterozygotes was similar to the rate $(34 \%$ and $39 \%)$ Dnd $1^{+/ T e r}$ heterozygote. These results suggest that DND1 ${ }^{\text {Ter }}$ protein has dosedependent effects on TGCT risk.

\section{Dnd $1^{\text {Ter }}$ and intestinal polyposis}

Although $D n d 1^{\text {Ter }}$ is a potent modifier of TGCT susceptibility, we speculated that the tumorigenic properties of $D n d 1^{T e r}$ may also be relevant in the intestine where Dnd1 is also expressed [52]. To test this hypothesis, we used the $\mathrm{Apc}^{+/ \mathrm{Min}}$ mouse model of intestinal polyposis. These mice develop numerous intestinal polyps at an early age and are a model of human Familial Adenomatous Polyposis (FAP) [53]. We crossed $D n d 1^{+/ T e r}$ and $A p c^{+/ M i n}$ mice to generate compound $A p c^{+/ M i n} D n d 1^{+/ T e r}$ heterozygotes (test) as well as a single-heterozygous $A p c^{+/ M i n} D n d 1^{+/+}$control. After 100 days of age, a significant 1.5 -fold increase in polyp number was observed in $A p c^{+/ M i n} D n d 1^{+/ T e r}$ doubleheterozygous test males compared to $A p c^{+/ M i n} \mathrm{Dnd} 1^{+/+}$ control males $(130 \pm 1.3$ and $96.2 \pm 1.4$, respectively; $\mathrm{t}=$ 4.4, $\mathrm{p}<0.001$, two-tailed t-test; Figure 3A). Similarly, total polyp mass was also significantly elevated from $192.2 \pm$ $11.6 \mathrm{~mm}^{2}$ in $\mathrm{Apc}^{+/ \mathrm{Min}} \mathrm{Dnd1^{+/+ }}$ mice to $352.6 \pm 11.4 \mathrm{~mm}^{2}$ in $A p c^{+/ M i n}:$ Dnd $1^{+/ T e r}$ males ( $\mathrm{t}=4.5, \mathrm{p}<0.0001$; two-tailed $\mathrm{t}$-test; Figure $3 \mathrm{~B})$, suggesting that a single copy of $D n d 1^{\text {Ter }}$

\section{Table 6 Occurrence of TGCTs-affected males of various} Dnd1 genotypes

\begin{tabular}{|c|c|c|c|}
\hline Genotype & Affected & Unaffected & Affected males (\%) (\%) \\
\hline$\neq$ Dnd $1^{+/+}$ & 6 & 34 & $15 \%$ \\
\hline$\neq D n d 1^{+/ K O}$ & 1 & 28 & $3 \%$ \\
\hline ₹Dnd1 $1^{+\pi T e r}$ & 14 & 27 & $34 \%$ \\
\hline$\neq$ Dnd $1^{K O / T e r}$ & 7 & 13 & $35 \%$ \\
\hline${ }^{*}$ Dnd1 ${ }^{+/ T e r}$ & 35 & 55 & $\neq 39 \%$ \\
\hline${ }^{*}$ Dnd $1^{\text {Ter/Ter }}$ & 45 & 1 & $\neq 98 \%$ \\
\hline
\end{tabular}

Dnd $1^{+/ K O}$ and $D n d 1^{+/ T e r}$ animals were intercrossed to test for occurrence of males with at least one TGCT. ₹ Offspring from Dnd $1^{+/ K O} \times D n d 1^{+/ T e r}$ crosses; * offspring from Dnd $1^{+/ T e r} \times D n d 1^{+/ T e r}$. $\neq$ Data are from Zechel et al. [51]. 


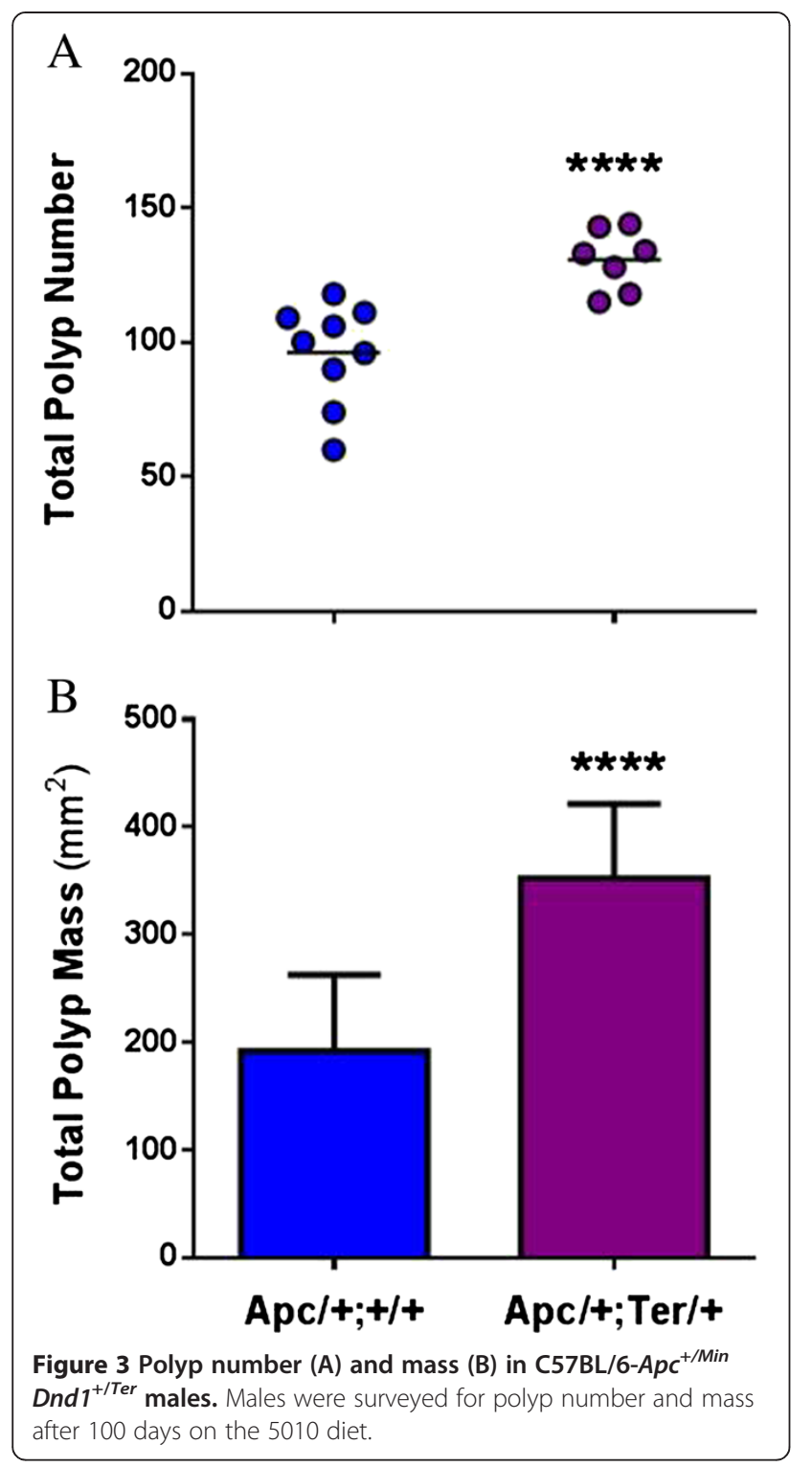

exacerbates intestinal polyp initiation and development in mice that are genetically susceptible to intestinal polyposis and that the action of Dnd1 ${ }^{\text {Ter }}$ is not limited

TGCTs.

\section{Discussion}

TGCTs are the third most heritable form of cancer, with approximately $25 \%$ of the susceptibility being attributed to underlying genetic factors [7]. The limited success in identifying genetic variants that account for a significant proportion of TGCT cases highlights the complex nature of TGCT susceptibility [54-56]. Discovery of the $\mathrm{gr} / \mathrm{gr}$ deletion, together with validated SNPs in the ATF7IP, BAK1, DMRT1, KITLG, SPRY4, TERT, HPGDS, MAD1L1, RFWD3, TEX14, RAD51C, PPM1E, DAZL and PRDM14 [12-19,57]. Even with these findings however, the majority of inherited TGCT susceptibility remains unknown. In the mouse, several TGCT susceptibility genes have been identified, including Kit, Kitlg, Pten, Dmrt1, Eif2s2 and others (for a review, see [58]). Together these human and mouse genes implicate pathways and functions related to germ cell proliferation, PGC differentiation and cell cycle control in TGCT development. But much remains to be learned about the nature of mutations in these genes that lead to tumorigenesis and about the ways that these molecular changes disrupt these pathways.

The current study suggests that Dnd1 ${ }^{\text {Ter }}$ is not a lossof-function allele, but instead affects TGCT risk and embryonic development in distinct ways from $D n d 1^{K O}$, a true loss-of-function mutation. The location of the point mutation found within Dnd1 does not conform to the "position of an exon-exon junction rule" for non-sense mediated decay [59]. The premature Ter stop codon is located 37 nucleotides upstream of the 3 '-most exonexon junction, within the 50-55 nucleotide range that fails to elicit nonsense-mediated decay (Figure 1). As a result, a translated DND1 ${ }^{\mathrm{Ter}}$ protein could be created consisting of Dnd1 exons 1-2 and part of exon 3, with an intact RRM but a disrupted HRAAAMA. The RRM within DND1 ${ }^{\text {Ter }}$ may still recognize its target mRNAs, but any functional or regulatory capabilities normally derived from the deleted portion of DND1 would be absent. This supposition is supported by work with the rat DND1 ${ }^{\text {Ter }}$ mutation, where the GFP-DND $1^{\text {Ter }}$ fusion protein is detectable in Huh7 cells [23]. The normal cellular processes that DND1 ${ }^{\mathrm{Ter}}$ might disrupt are numerous because RNA binding proteins have diverse functions, including alternative splicing, RNA stability, miRNA regulation, and translation control [60-63]. To date, antibodies are not available for mouse DND1, thereby precluding many obvious studies.

Recent work revealed an essential role of a putative ATPase domain in DND1 (RAAAE) in PGC survival [34]. This previously unannotated domain shares homology with RAAA (amino acids 178-181) in mouse DND1 where the arginine residue represents the amino acid substituted with a stop codon in Dnd1 $1^{\text {Ter }}$ [22]. Thus any ATPase activity in mouse DND1 possesses would be lost in DND1 ${ }^{\text {Ter }}$. This region is also part of a larger motif in DND1, HRAAAMA, which is highly conserved and found in many paralogous RNA binding proteins, including Apobec complementation factor (A1CF), suggesting that this motif is functionally important in this gene family (unpubl.).

Although DND1 ${ }^{\text {Ter }}$ appears to be a novel variant that increases TGCT risk, its tumorigenic effects are limited to the 129 strain of mice, which is not surprising, since this is the mouse strain that is susceptible to spontaneous TGCTs $[38,63]$. This finding highlights the importance of genetic background on TGCT susceptibility, 
which has been observed in humans, particularly in the disparate TGCT rates among ethnic groups $[4,64]$. The importance of genetic background is also evident in the interaction of DND1 $1^{\mathrm{Ter}}$ and mouse background. The 129 strain interacts positively with DND1 ${ }^{\text {Ter }}$ to increase TGCT risk, whereas C56BL/6J and other strains only exhibit phenotypes related to some but not all aspects of mutations in genes such as Kit, Kitl, Pten, Eif2s2I and other TGCT modifier genes, but not TGCTs $[55,65,66]$. However, the tumorigenic effects of $D n d 1^{T e r}$ are not limited to PGC transformation in the 129 strain mice. C57BL/6J mice with the $A p c^{M i n}$ mutation are highly susceptible to intestinal polyps [67]. However, when mice are compound heterozygotes for both $A p c^{\mathrm{Min}}$ and $D n d 1^{T e r}$, polyp numbers and polyp burden are significantly increased (Figure 3). These results suggest that DND1 ${ }^{\text {Ter }}$ affects pathways in both PGC transformation and intestinal polyposis.

Embryonic lethality is the usual interpretation for biased genotypic distributions in intercrosses, especially with complete loss of homozygous mutants. However this interpretation is difficult to reconcile with normal litter sizes. In particular, loss of $\sim 50 \%$ of intercross progeny (Table 1) should lead to average litter sizes that are $\sim 2$ rather than $\sim 4$ pups per litter (Table 3 ). We are aware of very few examples where substantial embryonic lethality does not affect litter size [68]. Instead, we propose that the unusual genotypic distributions result from biased allelic inheritance where specific combinations of oocyte and sperm are favored (or disfavored). Normal segregation in reciprocal backcrosses with the 129S1/SvImJ suggests that gametes are produced in sufficient numbers and are adequately functional (Table 3 ). Instead results for intercrosses suggest that deficits in both females and males are needed to bias allelic inheritance. Together these results suggest that the bias arises at fertilization. Interestingly, genetically and functionally related genes also show biased segregation, including Apobec1 and A1cf [47,48]

The contrasting effects of different classes of Dnd1 mutations may explain why sequencing studies failed to yield mutations within DND1 in human TGCT cases $[24,25]$. Complete loss of DND1 function is not sufficient to promote TGCT formation, even on the TGCTsusceptible 129S1/SvImJ inbred genetic background; reducing the chances that DND1 mutations play a significant role in human TGCTs. Results from zebrafish support this interpretation. Loss of Dnd1 inhibits PGC migration and results in PGC deficiency, but did not produce TGCTs [31]. TGCTs have been previously reported in zebrafish [35,49]. Dnd1 ${ }^{\text {Ter }}$ homozygotes also show reduced migration and loss of PGCs, with typically less than 20 PGCs arriving to the presumptive fetal gonads [21]. Instead, our results show that it is the loss of the carboxy-terminus of DND1 protein that increases TGCT risk. The role of DND1 ${ }^{\text {Ter }}$ in TGCT formation is further supported by recent results in a rat study where a spontaneous mutation producing a premature stop codon in exon 4, similar to $D N D 1^{T e r}$, resulted in TGCTs [23]. To date, human $D N D 1$ mutations have not yet been reported that yield a similarly truncated DND1 protein.

\section{Conclusions}

Through intercrosses with mice carrying a complete loss of function $D n d 1^{K O}$ allele our study showed that DND1 is necessary for embryonic viability and results in abnormal allelic segregation. We have further shown that $D n d 1^{T e r}$, previously believed to be a loss-of-function allele, is likely translated into a protein that retains some normal DND1 function. Crosses with the Dnd1 knockout and Ter alleles revealed that the effects of the Ter allele on TGCT incidence depend on Ter dosage. Expression of the Ter allele in an $A P C^{M i n}$ model of intestinal polyposis also significantly increased polyp burden. These results demonstrate that $D n d 1^{T e r}$ enhances tumorigenesis in two separate mouse models of cancer.

\section{Methods}

Mice

\section{S1/SvImJ}

This strain (JR002448, previously known as 129/SvImJ) was obtained from the Jackson Laboratory (Bar Harbor, ME, USA). All studies were conducted on this inbred genetic background.

\section{S1/SvImJ-Dnd $1^{+/ K O}$}

ES cells with a targeted deletion of Dnd1 were generated from $129 S 6$ mice by the Intrexon Corporation, (Blacksburg, VA). Exons 1-2 and most of exon 3 of Dnd1 were removed through homologous recombination (Additional file 2: Figure S2), and cells were negatively selected with thymidine kinase (TK) and diphtheria toxin A (DTA), and positively selected with neomycin. PCR was used to confirm homologous recombination in these cells. ES cells were then injected into blastocysts (Case Transgenic and Targeting Facility) and the resulting chimeras were backcrossed onto the $129 \mathrm{~S} 1 / \mathrm{SvImJ}$ strain for more than 10 generations.

C57BL/6J (B6; JR000664) and C57BL/6J-Apc $c^{+/ M i n}$ $\left(\mathrm{Apc}^{+/ \mathrm{Min}}\right.$; JR002020) mice were purchased from the Jackson Laboratory (Bar Harbor, ME).

From birth to 30 days of age, all mice were fed an autoclaved standard laboratory diet (Purina 5010 LabDiet (Richmond, IN) and were provided autoclaved water ad libitum. All mice were maintained on a 12-h light/dark cycle at the Wolstein Research Facility (CWRU).

Procedures were approved and conducted in compliance with Institutional Animal Care and Use Committee (IACUC) standards at (CWRU). 


\section{Embryonic day 3.5 (E3.5) embryo cultures}

Embryos from time-mated $D n d 1^{+/ K O} \times \mathrm{Xnd1}^{+/ K O}$ pregnant females were flushed from the oviducts and uterine horns on embryonic day 3.5 (E3.5) and cultured as previously described [69]. To obtain sufficient material for reproducible genotyping, embryos were cultured for 1 week in individual wells of a 24-well tissue culture plate

\section{Genotyping}

DNA for PCR genotyping was extracted from tail tissue (mice) or cell masses (E3.5 embryo cultures). The nucleotide substitution in the Ter mutation results in the creation of a Dde1 site that was used for genotyping [22]. The $D n d 1^{K O}$ allele was amplified using primers extending from exon 4 of Dnd1 into the neomycin gene of the targeting construct. The $D n d 1^{K O}$ primers are: CTGCGTGTTCGAATTCGCCAATGA (F), ACAAAG AGAAACCCGGTCTCGGAA (R). Primers used for genotyping $A p c^{+/ M i n}$ were previously described [67].

\section{Tumor surveys}

Male mice between the ages of 4-16 weeks were surveyed for TGCTs. Tumor incidence was calculated as the percentage of males with at least one TGCT. Histological analysis (H\&E staining, see below) was used to confirm any TGCTs that were ambiguous at autopsy.

\section{Intestinal polyp survey}

Mice were euthanized with cervical dislocation. The small and large intestines were immediately removed, flushed with cold PBS, and cut longitudinally for polyp measurements. Polyps were counted and cross-sectional diameter was measured in the small intestine and colon with a Leica MZ10F Modular Stereomicroscope. Individual polyp size and number were used to calculate a measure of total polyp mass for each mouse, and this measure was used as a surrogate for polyp burden.

\section{Histology}

Testes were fixed with $10 \%$ formalin for at least $48 \mathrm{~h}$. Tissues were then embedded in paraffin and sectioned $(5 \mu \mathrm{m})$ at the Case Comprehensive Cancer Center Tissue Procurement and Histology Core facility (TPHC). Hematoxylin and eosin staining was done in the TPHC facility.

\section{Quantitative real-time PCR}

RNA was extracted from cells and tissues using the RNeasy micro- and mini-kits, respectively (Qiagen Inc., Valencia, CA) according to the manufacturer's instructions and including an on-column DNAse treatment. RNA was reverse-transcribed using the qScript Synthesis Kit (Quanta BioSciences Inc., Gaithersburg, MD). Changes in relative expression were quantified with the Chromo4 real-time PCR system (MJ Research) and
TaqMan primers to Dnd1(Invitrogen \#Mm00849348) and normalized to 18S (Invitrogen \#4319413E) using manufacturer protocols and reported as mean \pm SEM.

\section{Statistical analysis}

Data are presented as mean \pm SEM. Two-tailed $t$-tests were used to evaluate results for quantitative PCR and data for both polyp numbers and burden. Chi-square contingency tests were used evaluate differences in occurrence of TGCT-affected males. Standard goodness-of-fit tests were used to evaluate differences between observed and Mendelian expectations for backcross and intercross segregation results. Then, to estimate the extent of loss for particular genotypes, the number of wild-type $(+/+)$ mice (or embryos) was taken as the expected number for this genotypic class, and assuming Mendelian segregation (i.e. 1:2:1), the expected number of mutant heterozygotes and homozygotes was calculated. The difference between these observed and expected numbers was used to estimate the extent of loss for each genotypic class.

\section{Additional files}

Additional file 1: Figure S1. Testis weight and histology in $\mathrm{Dndl}^{+/+}$and Dnd $1^{+K O}$. (A) Testes were removed and weighed from mice aged 6 to 10 weeks. Testes weights from adult heterozygous Dnd1-deficient males (Het, Dnd $1^{+/ K g}$ and their wild-type control littermates (WT, Dnd $1^{+/+}$) were similar. Testes from wild-type males (WT) weighed an average of $4.43 \pm 0.88 \mathrm{~g}$, compared to testes from heterozygous Dnd $1^{+/ K O}$ males $(4.44 \pm 0.69 \mathrm{~g})$. Body weights did not differ significantly between WT (Dnd ${ }^{+/ K G}$ ) and heterozygous (Dnd1 ${ }^{+/ K 9}$ ) animals (data not shown). Histology of these testes show no morphological differences between Dnd $1^{+/+}$(B) and Dnd $1^{+/ K O}$

(C). These results suggest that testes in Dnd $1^{+/ K O}$ males do not show significant germ cell deficiency.

Additional file 2: Figure S2. Generation of Dnd $1^{K O}$ knockout mice. (A) Genomic Dnd1 locus showing flanking Hars and Wdr55 genes. Exons are shown as boxes and arrows show the direction of transcription. The left and right homology arms of the targeting construct are indicated. Following homologous recombination, exons 1,2 and a portion of 3 of Dnd 1 are removed and a neomycin selection unit is introduced. The triangle next to the neomycin unit indicates direction of transcription. The Hars and Wdr55 genes remain intact.

\section{Abbreviations}

TGCT: Testicular germ cell tumor; SNP: Single nucleotide polymorphism; RRM: RNA recognition motif; PGC: Primordial germ cell; GFP: Green fluorescent protein.

\section{Competing interests}

The authors declare that they have no competing interests.

\section{Authors' contributions}

$J \mathrm{JZ}$ and JHN conceived of the study, JLZ did the work with the exception of the data provided in Figure 3, which was conducted and analyzed by SKD. PJT did the embryo flushes and culturing. JDH assisted with initial transgenic mouse creation, experimental design and intellectual input. JHN assisted with the statistical analysis. JLZ and JHN wrote the original draft with editing done by AL, SKD and JDH. All authors read and approved of the final version.

\section{Acknowledgments}

We thank Sabine Schaefer for her helpful comments on a draft of this paper. $\mathrm{NCl}$ grant CA75056 supported this work. 


\section{Author details}

'Department of Genetics and Genome Sciences, Case Western Reserve University School of Medicine, Cleveland OH 44106, USA. ${ }^{2}$ Department of Molecular and Human Genetics, Baylor College of Medicine, Houston, TX 77030, USA. ${ }^{3}$ Pacific Northwest Research Institute, 720 Broadway, Seattle, WA 98122, USA.

Received: 24 March 2013 Accepted: 7 June 2013

Published: 17 June 2013

\section{References}

1. Di PA, Vries EG, Gietema JA, Spierings DC, de JS: Testicular germ cell tumours: the paradigm of chemo-sensitive solid tumours. Int J Biochem Cell Biol 2005, 37:2437-2456.

2. Buetow SA: Epidemiology of testicular cancer. Epidemiol Rev 1995, 17:433-449.

3. Bosl GJ, Motzer RJ: Testicular germ-cell cancer. N Engl J Med 1997, 337:242-253.

4. Chia VM, Quraishi SM, Devesa SS, Purdue MP, Cook MB, McGlynn KA International trends in the incidence of testicular cancer, 1973-2002. Cancer Epidemiol Biomarkers Prev 2010, 19:1151-1159.

5. Jemal A, Simard EP, Dorell C, Noone AM, Markowitz LE, Kohler B, Eheman C, Saraiya M, Bandi P, Saslow D: Annual report to the Nation on the Status of cancer, 1975-2009, Featuring the Burden and trends in Human Papillomavirus (HPV)-Associated cancers and HPV Vaccination coverage levels. J Natl Cancer Inst 2013, 105:175-201.

6. Edsgard D, Dalgaard MD, Weinhold N, Wesolowska-Andersen A, Rajpert-De Meyts E, Ottesen AM, Juul A, Skakkebæk NE, Jensen TS, Gupta R: Genomewide assessment of the association of rare and common copy number variations to testicular germ cell cancer. Endocrinology: Frontiers in; 2013:4.

7. Heimdal K, Olsson H, Tretli S, Fossa SD, Borresen AL, Bishop DT: A segregation analysis of testicular cancer based on Norwegian and Swedish families. Br J Cancer 1997, 75:1084-1087.

8. Chia VM, Li Y, Goldin LR, Graubard BI, Greene MH, Korde L, Rubertone MV: Erickson RL. McGlynn KA: Risk of cancer in first- and second-degree relatives of testicular germ cell tumor cases and controls. Int J Cancer; 2008.

9. Neale RE, Carriere P, Murphy MF, Baade PD: Testicular cancer in twins: a meta-analysis. $\mathrm{Br} J$ Cancer 2008, 98:171-173.

10. Hemminki K, Li X: Familial risk in testicular cancer as a clue to a heritable and environmental aetiology. Br J Cancer 2004, 90:1765-1770.

11. Nathanson KL, Kanetsky PA, Hawes R, Vaughn DJ, Letrero R, Tucker K Friedlander M, Phillips KA, Hogg D, Jewett MA, et al: The Y deletion gr/gr and susceptibility to testicular germ cell tumor. Am J Hum Genet 2005, 77:1034-1043

12. Turnbull C, Rapley EA, Seal S, Pernet D, Renwick A, Hughes D, Ricketts M, Linger R, Nsengimana J, Deloukas P, et al: Variants near DMRT1, TERT and ATF7IP are associated with testicular germ cell cancer. Nat Genet 2010 42:604-607.

13. Kratz CP, Han SS, Rosenberg PS, Berndt SI, Burdett L, Yeager M, Korde LA Mai PL, Pfeiffer R, Greene MH: Variants in or near KITLG, BAK1, DMRT1, and TERT-CLPTM1L predispose to familial testicular germ cell tumour. J Med Genet 2011, 48:473-476.

14. Poynter JN, Hooten AJ, Frazier AL, Ross JA: Associations between variants in KITLG, SPRY4, BAK1, and DMRT1 and pediatric germ cell tumors. Genes Chromosomes Cancer 2012, 51:266-271.

15. Rapley EA, Turnbull C, Al Olama AA, Dermitzakis ET, Linger R, Huddart RA Renwick A, Hughes D, Hines S, Seal S, et al: A genome-wide association study of testicular germ cell tumor. Nat Genet 2009, 41:807-810.

16. Kanetsky PA, Mitra N, Vardhanabhuti S, Vaughn DJ, Li M, Ciosek SL, Letrero $R$, D'Andrea K, Vaddi M, Doody DR, et al: A second independent locus within DMRT1 is associated with testicular germ cell tumor susceptibility. Hum Mol Genet 2011, 20:3109-3117.

17. Kanetsky PA, Mitra N, Vardhanabhuti S, Li M, Vaughn DJ, Letrero R, Ciosek SL, Doody DR, Smith LM, Weaver J, et al: Common variation in KITLG and at 5q31.3 predisposes to testicular germ cell cancer. Nat Genet 2009, 41:811-815.

18. Chung CC, Kanetsky PA, Wang Z, Hildebrandt MA, Koster R, Skotheim RI, Kratz CP, Turnbull C, Cortessis VK, Bakken AC: Meta-analysis identifies four new loci associated with testicular germ cell tumor. Nat Genet 2013, 45:680-685.

19. Ruark E, Seal S, McDonald H, Zhang F, Elliot A, Lau K, Perdeaux E, Rapley E, Eeles $\mathrm{R}$, Peto J: Identification of nine new susceptibility loci for testicular cancer, including variants near DAZL and PRDM14. Nat Genet 2013, 45:686-689.
20. Kohno T, Kunitoh H, Shimada $Y$, Shiraishi K, Ishii $Y$, Goto K, Ohe Y, Nishiwaki $Y$, Kuchiba A, Yamamoto S: Individuals susceptible to lung adenocarcinoma defined by combined HLA-DQA1 and TERT genotypes. Carcinogenesis 2010, 31:834-841.

21. Noguchi T, Noguchi M: A recessive mutation (ter) causing germ cell deficiency and a high incidence of congenital testicular teratomas in 129/Sv-ter mice. J Natl Cancer Inst 1985, 75:385-392.

22. Youngren KK, Coveney D, Peng $X$, Bhattacharya C, Schmidt LS, Nickerson ML, Lamb BT, Deng JM, Behringer RR, Capel B, et al: The Ter mutation in the dead end gene causes germ cell loss and testicular germ cell tumours. Nature 2005, 435:360-364.

23. Northrup E, Zschemisch NH, Eisenblatter R, Glage S, Wedekind D, Cuppen E, Dorsch $\mathrm{M}$, Hedrich $\mathrm{HJ}$ : The ter mutation in the rat Dnd1 gene initiates gonadal teratomas and infertility in both genders. PLoS One 2012, 7:e38001.

24. Sijmons RH, Vos YJ, Herkert JC, Bos KK, Holzik MF, Hoekstra-Weebers JE, Hofstra RM, Hoekstra HJ: Screening for germline DND1 mutations in testicular cancer patients. Fam Cancer 2010, 9:439-442.

25. Linger R, Dudakia D, Huddart R, Tucker K, Friedlander M, Phillips KA, Hogg $D$, Jewett MA, Lohynska R, Daugaard G, et al: Analysis of the DND1 gene in men with sporadic and familial testicular germ cell tumors. Genes Chromosomes Cancer 2008, 47:247-252.

26. Kedde M, Strasser MJ, Boldajipour B, Oude Vrielink JA, Slanchev K, Le SC, Nagel $R$, Voorhoeve PM, Van DJ, Orom UA, et al: RNA-binding protein Dnd1 inhibits microRNA access to target mRNA. Cell 2007, 131:1273-1286.

27. Zhu R, lacovino M, Mahen E, Kyba M, Matin A: Transcripts that associate with the RNA binding protein, DEAD-END (DND1), in embryonic stem (ES) cells. BMC Mol Biol 2011, 12:37.

28. Cook MS, Munger SC, Nadeau JH, Capel B: Regulation of male germ cell cycle arrest and differentiation by DND1 is modulated by genetic background. Development 2011, 138:23-32.

29. Chen S, Zeng M, Sun H, Deng W, Lu Y, Tao D, Liu Y, Zhang S, Ma Y: Zebrafish Dnd protein binds to $3^{\prime} U T R$ of geminin mRNA and regulates its expression. BMB Rep 2010, 43:438-444

30. Slanchev K, Stebler J, Goudarzi M, Cojocaru V, Weidinger G, Raz E: Control of Dead end localization and activity「Çôlmplications for the function of the protein in antagonizing miRNA function. Mech Dev 2009, 126:270-277.

31. Weidinger G, Stebler J, Slanchev K, Dumstrei K, Wise C, Lovell-Badge R, Thisse $C$, Thisse B, Raz E: dead end, a novel vertebrate germ plasm component, is required for zebrafish primordial germ cell migration and survival. Curr Biol 2003, 13:1429-1434.

32. Stevens LC: Origin of testicular teratomas from primordial germ cells in mice. J Natl Cancer Inst 1967, 38:549-552.

33. Bhattacharya C, Aggarwal S, Zhu R, Kumar M, Zhao M, Meistrich ML, Matin $A$ : The mouse dead-end gene isoform alpha is necessary for germ cell and embryonic viability. Biochem Biophys Res Commun 2007, 355:194-199.

34. Liu W, Collodi P: Zebrafish dead end possesses ATPase activity that is required for primordial germ cell development. FASEB J 2010, 24:2641-2650.

35. Neumann JC, Chandler GL, Damoulis VA, Fustino NJ, Lillard K, Looijenga L, Margraf L, Rakheja D, Amatruda JF: Mutation in the type IB bone morphogenetic protein receptor alk6b impairs germ-cell differentiation and causes germ-cell tumors in zebrafish. Proc Natl Acad Sci 2011, 108:13153-13158.

36. Neumann JC, Lillard K, Damoulis V, Amatruda JF: Zebrafish Models of Germ Cell Tumor. In The Zebrafish: Disease Models and Chemical Screens. 3rd edition. Edited by Detrich HW, Westerfield M, Zon LI. San Diego: Academic Press; 2011:4-24

37. Gill JA, Lowe L, Nguyen J, Liu PP, Blake T, Venkatesh B, Aplan PD: Enforced Expression of Simian Virus 40 Large T-Antigen Leads to Testicular Germ Cell Tumors in Zebrafish. Zebrafish 2010, 7:333-341.

38. Stevens LC, Hummel KP: A description of spontaneous congenital testicular teratomas in strain 129 mice. J Natl Cancer Inst 1957 18:719-747.

39. Stevens LC: A new inbred subline of mice (129-terSv) with a high incidence of spontaneous congenital testicular teratomas. J Nat/ Cancer Inst 1973, 50:235-242.

40. Stevens LC: Mackensen. Genetic and environmental influences on teratocarcinogenesis in mice: JA; 1961

41. Castillejo A, Sanchez-Heras AB, Jover R, Castillejo Ml, Guarinos C, Oltra S, Martinez-Canto A, Barbera VM, Laforga J, Paya A, et al: Recurrent testicular germ cell tumors in a family with MYH-associated polyposis. J Clin Oncol 2012, 30:e216-e217. 
42. Larsson E, Tremaroli V, Lee YS, Koren O, Nookaew I, Fricker A, Nielsen J, Ley RE, Bäckhed F: Analysis of gut microbial regulation of host gene expression along the length of the gut and regulation of gut microbial ecology through MyD88. Gut 2012, 61:1124-1131.

43. Mutch DM, Crespy V, Clough J, Henderson CJ, Lariani S, Mansourian R, Moulin J, Wolf CR, Williamson G: Hepatic cytochrome P-450 reductase-null mice show reduced transcriptional response to quercetin and reveal physiological homeostasis between jejunum and liver. Am J Physiol Gastrointest Liver Physiol 2006, 291:G63-G72.

44. Thorrez L, Laudadio I, Van Deun K, Quintens R, Hendrickx N, Granvik M, Lemaire K, Schraenen A, Van Lommel L, Lehnert S: Tissue-specific disallowance of housekeeping genes: the other face of cell differentiation. Genome Res 2011, 21:95-105.

45. Saito S, Furuno A, Sakurai J, Sakamoto A, Park HR, Shin-ya K, Tsuruo T, Tomida A: Chemical genomics identifies the unfolded protein response as a target for selective cancer cell killing during glucose deprivation. Cancer Res 2009, 69:4225-4234.

46. Horst D, Chen J, Morikawa T, Ogino S, Kirchner T, Shivdasani RA: Differential WNT activity in colorectal cancer confers limited tumorigenic potential and is regulated by MAPK signaling. Cancer Res 2012, 72:1547-1556.

47. Nelson VR, Heaney JD, Tesar PJ, Davidson NO, Nadeau JH: Transgenerational epigenetic effects of the Apobec1 cytidine deaminase deficiency on testicular germ cell tumor susceptibility and embryonic viability. Proc Natl Acad Sci 2012, 109:E2766-E2773.

48. Blanc V, Henderson JO, Newberry EP, Kennedy S, Luo J, Davidson NO: Targeted deletion of the murine apobec-1 complementation factor (acf) gene results in embryonic lethality. Mol Cell Biol 2005, 25:7260-7269.

49. Collin GB, Asada Y, Varnum DS, Nadeau JH: DNA pooling as a quick method for finding candidate linkages in multigenic trait analysis: an example involving susceptibility to germ cell tumors. Mamm Genome 1996, 7:68-70

50. Lam MY, Heaney JD, Youngren KK, Kawasoe JH, Nadeau JH: Transgenerational epistasis between Dnd1Ter and other modifier genes controls susceptibility to testicular germ cell tumors. Hum Mol Genet 2007, 16:2233-2240.

51. Zechel JL, MacLennan GT, Heaney JD, Nadeau JH: Spontaneous metastasis in mouse models of testicular germ-cell tumours. Int J Androl 2011, 34 e278-e287.

52. Detwiller KY, Fernando NT, Segal NH, Ryeom SW, D'Amore PA, Yoon SS: Analysis of hypoxia-related gene expression in sarcomas and effect of hypoxia on RNA interference of vascular endothelial cell growth factor A. Cancer Res 2005, 65:5881-5889.

53. Su LK, Kinzler KW, Vogelstein B, Preisinger AC, Moser AR, Luongo C, Gould KA, Dove WF: Multiple intestinal neoplasia caused by a mutation in the murine homolog of the APC gene. Science 1992, 256:668-670.

54. Kratz CP, Greene MH, Bratslavsky G, Shi J: A stratified genetic risk assessment for testicular cancer. Int J Androl 2011, 34:e98-102.

55. Lam MY, Youngren KK, Nadeau JH: Enhancers and suppressors of testicular cancer susceptibility in single- and double-mutant mice. Genetics 2004, 166:925-933

56. Stevens LC: The biology of teratomas. Adv Morphog 1967, 6:1-31.

57. Landi MT, Chatterjee N, Yu K, Goldin LR, Goldstein AM, Rotunno M, Mirabello L, Jacobs K, Wheeler W, Yeager M, et al: A genome-wide association study of lung cancer identifies a region of chromosome 5 p15 associated with risk for adenocarcinoma. Am J Hum Genet 2009, 85:679-691.

58. Carouge D, Nadeau JH: Mouse Models of Testicular Germ Cell Tumors. In Germ Cell Tumor. 1st edition. Edited by Matin A. Manhattan: InTech; 2012:75-106.

59. Maquat LE: Nonsense-mediated mRNA decay: splicing, translation and mRNP dynamics. Nat Rev Mol Cell Biol 2004, 5:89-99.

60. Bandziulis RJ, Swanson MS, Dreyfuss G: RNA-binding proteins as developmental regulators. Genes Dev 1989, 3:431-437.

61. Fry DC, Kuby SA, Mildvan AS: ATP-binding site of adenylate kinase: mechanistic implications of its homology with ras-encoded p21, F1 ATPase, and other nucleotide-binding proteins. Proc Natl Acad Sci USA 1986, 83:907-911.

62. Query CC, Bentley RC, Keene JD: A specific 31-nucleotide domain of U1 RNA directly interacts with the 70K small nuclear ribonucleoprotein component. Mol Cell Biol 1989, 9:4872-4881.

63. Courage D, Nadeau JH: Mouse Models of Testicular Germ Cell Tumors. In Germ Cell Tumor. Edited by Matin A. InTech; 2012. 6-7-2012.
64. Testicular cancer - UK incidence statistics. http://info.cancerresearchuk.org/ cancerstats/types/testis/incidence/uk-testicular-cancer-incidence-statistics.

65. Zhu R, Heaney J, Nadeau JH, Ali S, Matin A: Deficiency of splicing factor 1 suppresses the occurrence of testicular germ cell tumors. Cancer Res 2010, 70:7264-7272.

66. Krentz AD, Murphy MW, Zhang T, Sarver AL, Jain S, Griswold MD, Bardwell VJ, Zarkower D: Interaction between DMRT1 function and genetic background modulates signaling and pluripotency to control tumor susceptibility in the fetal germ line. Dev Biol 2013, 377:67-78.

67. Moser AR, Pitot HC, Dove WF: A dominant mutation that predisposes to multiple intestinal neoplasia in the mouse. Science 1990, 247:322-324.

68. Landrock D, Atshaves BP, McIntosh AL, Landrock KK, Schroeder F, Kier AB: Acyl-CoA binding protein gene ablation induces pre-implantation embryonic lethality in mice. Lipids 2010, 45:567-580.

69. Tesar PJ: Derivation of germ-line-competent embryonic stem cell lines from preblastocyst mouse embryos. Proc Natl Acad Sci USA 2005 102:8239-8244.

doi:10.1186/1471-2156-14-54

Cite this article as: Zechel et al:: Contrasting effects of Deadend1 (Dnd1) gain and loss of function mutations on allelic inheritance, testicular cancer, and intestinal polyposis. BMC Genetics 2013 14:54.

\section{Submit your next manuscript to BioMed Central and take full advantage of:}

- Convenient online submission

- Thorough peer review

- No space constraints or color figure charges

- Immediate publication on acceptance

- Inclusion in PubMed, CAS, Scopus and Google Scholar

- Research which is freely available for redistribution
Biomed Central 